Research Article

\title{
Trend of malarial deaths admitted in medicine wards of a tertiary care centre at Cuttack, Odisha, India
}

\author{
Nitin H. Kamble ${ }^{1 *}$, Manoj K. Dash ${ }^{2}$, Durga M. Satapathy ${ }^{3}$ \\ ${ }^{1}$ Department of Community Medicine, Government Medical College, Chandrapur, Maharashtra, India \\ ${ }^{2}$ Department of Community Medicine, S.C.B. Medical College, Cuttack, Odisha, India \\ ${ }^{3}$ Department of Community Medicine, V.I.M.S.A.R., Burla, Odisha, India
}

Received: 18 March 2016

Revised: 19 March 2016

Accepted: 07 May 2016

*Correspondence:

Dr. Nitin H. Kamble,

E-mail: dr.nitinkamble73@gmail.com

Copyright: () the author(s), publisher and licensee Medip Academy. This is an open-access article distributed under the terms of the Creative Commons Attribution Non-Commercial License, which permits unrestricted non-commercial use, distribution, and reproduction in any medium, provided the original work is properly cited.

\section{ABSTRACT}

Background: Malaria is one of the most important vector borne diseases causing significant morbidity and mortality. The trend of malaria cases in a tertiary care institution will reflect the changes in burden of disease in health care centers. There is a need to look at the malaria mortality, morbidity and its contributing factors in tertiary care institutions in the state. On this background an attempt has been made to undertake three year retrospective record based analysis of malarial deaths in Medicine Department of S.C.B. Medical College, Cuttack. Objective of the study is to study the trend of malaria fatalities in a tertiary care center.

Methods: Retrospective record based descriptive study. The data was collected from the bed tickets in the record room of SCB Medical College, Cuttack, over 3 calendar years i.e. 2010, 2011 and 2012, using predesigned and pretested formats. The data thus collected were analysed using statistical software i.e. SPSS v11.

Results: The total number of fatalities reported over the total of three calendar years was 1934. The absolute number of deaths due to malaria over each of the three years 2010, 2011 and 2012 were 594, 630 and 710 respectively. The trend thus is an increasing number of fatalities attributed to malaria.

Conclusions: The trend of malarial deaths shows that malaria continues to be the one of the largest contributors of mortality even in tertiary care institutions and in absolute numbers it shows an increasing trend over the three years for which data has collected.

Keywords: Malaria, Trends of malarial deaths, Tertiary care center, Fatality

\section{INTRODUCTION}

Malaria is one of the major public health problems of the country. It is a protozoa disease infection with parasites of the genus plasmodium and transmitted to man by certain species of infected female anopheline mosquito. ${ }^{1}$ According to the World Malaria Report 2012, globally an estimated 3.3 billion people were at risk of malaria in 2011, with populations living in sub-saharan Africa having the highest risk of acquiring malaria: approximately $80 \%$ of cases and $90 \%$ of deaths are estimated to occur in the WHO African Region, with children under five years of age and pregnant women most severely affected. ${ }^{2}$ According to official data of NVBDCP, about $95 \%$ population in the country resides in malaria endemic areas and $80 \%$ of malaria reported in the country is confined to areas consisting $20 \%$ of population residing in tribal, hilly, difficult and inaccessible areas. There are two types of parasites of human malaria, Plasmodium vivax (Pv), P. Falciparum (Pf), which are commonly reported from India. ${ }^{3}$ There are six primary vectors of malaria in India: An. culicifacies, 
An. stephensi, An. fluviatilis, An. mimimus, An. dirus and An. epiroticus. ${ }^{4}$ On this background an attempt has been made to undertake three year retrospective record based analysis of malaria cases admitted to Medicine Department of S.C.B. Medical College, Cuttack.

\section{METHODS}

The present study was record based retrospective and descriptive study. The study was conducted at medical record section of S. C. B. Medical College and Hospital, Cuttack. In this study an attempt has been made to review the bed head tickets of those patients admitted to medicine department during the period between $1^{\text {st }}$ January 2010 and $31^{\text {st }}$ December 2012. Duration of study was 12 months $\left(1^{\text {st }}\right.$ October 2013 to $30^{\text {th }}$ September 2014). The sampling process was a total enumeration sampling i.e. all bed tickets filed in the central record room and available on retrieval as well and pertaining to reference period of the study. All death tickets in the reference period were screened.

All the bed head tickets of indoor patients admitted to Medicine department during the same period will be screened and those cases found to be positive for malaria will considered for the present study. Where no final diagnosis was clearly mentioned, the provisional and final diagnosis was assumed as same. The bed tickets with the diagnosis clinical malaria thoroughly be studied, reviewed and necessary data and information collected in predesigned schedule. The schedule was designed to collect necessary and relevant information from the bed head tickets of malaria patients as per study objectives. The results were analysed using MS Excel v2007 and SPSS v11 software.

The limitation of study was sample drawn was based on availability of medical records for the Departments of medicine in the central records room at SCB Medical College. Due to lack of systematic filing of medical records all IPD records were not available.

\section{RESULTS}

The analysis of cases admitted to SCBMCH over the three study years 2010-2012, shows an increasing trend. All the discharge tickets of the medicine department accessible from the central record room were screened for malaria.

Table 1: Year wise trend of malaria cases.

\begin{tabular}{|lll|}
\hline Year & $\begin{array}{l}\text { Provisional } \\
\text { malaria diagnosis }\end{array}$ & $\begin{array}{l}\text { Final malaria } \\
\text { diagnosis }\end{array}$ \\
\hline 2010 & 2250 & 1895 \\
\hline 2011 & 3166 & 2589 \\
\hline 2012 & 3890 & 3362 \\
\hline Total & 9306 & 7846 \\
\hline
\end{tabular}

Table 1 shows a total of 9306 discharge tickets were found to have a provisional diagnosis of malaria with 2250, 3166 and 3890 tickets from the years 2010, 2011 and 2012 respectively. From among these bed tickets 7846 bed tickets had malaria in the final diagnosis. These 7846 cases with final diagnosis were taken as the clinical malaria cases.

Table 2: Trends in case fatality ratio of clinical malaria cases.

\begin{tabular}{|lllll|}
\hline Year & Fatal & Nonfatal & Total & $\begin{array}{l}\text { Case } \\
\text { fatality } \\
\text { ratio }\end{array}$ \\
\hline 2010 & 594 & 1301 & 1895 & 0.31 \\
\hline 2011 & 630 & 1959 & 2589 & 0.24 \\
\hline 2012 & 710 & 2652 & 3362 & 0.21 \\
\hline Total & 1934 & 5912 & 7846 & 0.24 \\
\hline
\end{tabular}

Table 3: Trends in proportional mortality rate $(n=1934)$.

\begin{tabular}{|lllll|}
\hline Outcome & $\mathbf{2 0 1 0}$ & $\mathbf{2 0 1 1}$ & $\mathbf{2 0 1 2}$ & Total \\
\hline Malaria deaths & 594 & 630 & 710 & 1934 \\
\hline Total deaths & 6400 & 7078 & 8073 & 21551 \\
\hline $\begin{array}{l}\text { Proportional } \\
\text { mortality rate (\%) }\end{array}$ & 9.28 & 8.90 & 8.79 & 8.97 \\
\hline Month & 2010 & 2011 & 2011 & Total \\
\hline January & 30 & 23 & 41 & 94 \\
\hline February & 35 & 22 & 24 & 81 \\
\hline March & 47 & 33 & 37 & 117 \\
\hline April & 39 & 27 & 32 & 98 \\
\hline May & 45 & 26 & 51 & 122 \\
\hline June & 46 & 42 & 49 & 137 \\
\hline July & 58 & 64 & 62 & 184 \\
\hline August & 62 & 105 & 116 & 283 \\
\hline September & 49 & 73 & 100 & 222 \\
\hline October & 64 & 96 & 80 & 240 \\
\hline November & 71 & 62 & 72 & 205 \\
\hline December & 48 & 57 & 46 & 151 \\
\hline Total & 594 & 630 & 710 & 1934 \\
\hline
\end{tabular}

Table 4: Distribution of malaria fatalities by gender.

\begin{tabular}{|llll|}
\hline Year & Male (\%) & Female $(\%)$ & Total $(\%)$ \\
\hline 2010 & $338(57 \%)$ & $256(43 \%)$ & $594(100 \%)$ \\
\hline 2011 & $403(64 \%)$ & $227(36 \%)$ & $630(100 \%)$ \\
\hline 2012 & $412(58 \%)$ & $298(42 \%)$ & $710(100 \%)$ \\
\hline Total & $1153(60 \%)$ & $781(40 \%)$ & $1934(100 \%)$ \\
\hline
\end{tabular}

Table 2 shows that out of total 7846 clinical malaria cases 1934 were died due to malaria and rest 5912 had survived. The malaria cases survived in years 2010, 2011 and 2012 were 1301, 1959 and 2652 respectively. The case fatality ratio of clinical malaria was $0.31,0.24$ and 0.21 for 2010, 2011 and 2012 respectively. The cumulative case fatality ratio was 0.24 . 
Table 3 shows that proportional mortality rate shows a steady decline over the years in malaria cases. Proportional mortality rate due to malaria was $8.97 \%$ for three years. It was $9.28 \%$ for the year $2010,8.90 \%$ for the year 2011 and $8.79 \%$ for the year 2012. Table shows that cumulative total of about 21551 fatalities have been recorded at SCBMCH over the three calendar years. Total deaths in medical college were 6400, 7078 and 8073 in the year 2010, 2011 and 2012 respectively. The numbers of fatalities have registered an increasing trend over the three years. This correlates with the increased numbers of patients admitted to this institution. Out of all fatalities clinical malaria contributes to 1934 deaths in those three years. From all the inpatient admitted to SCBMCH, all the death tickets i.e. about 21551 were screened for malaria. A total of 1934 death tickets i.e. 594, 630 and 710 case tickets were found to have a clinical diagnosis of malaria in the years 2010, 2011 and 2012 respectively.

Table 3 states the analysis of data of the seasonal (monthly) distribution of fatalities shows that the peak of the case load is from the month of June onwards and the upward swing of the case load continues up to October and then tapers down with a small secondary peak in late November and December.

The data from Table 4 showed that fatality in males outnumbered females while being treated for clinical malaria in this institution for consecutive three years (2010, 2011 and 2012). The preponderance of males noteworthy since the ratio of fatality between the sexes (male: female) is 3:2 in three years.

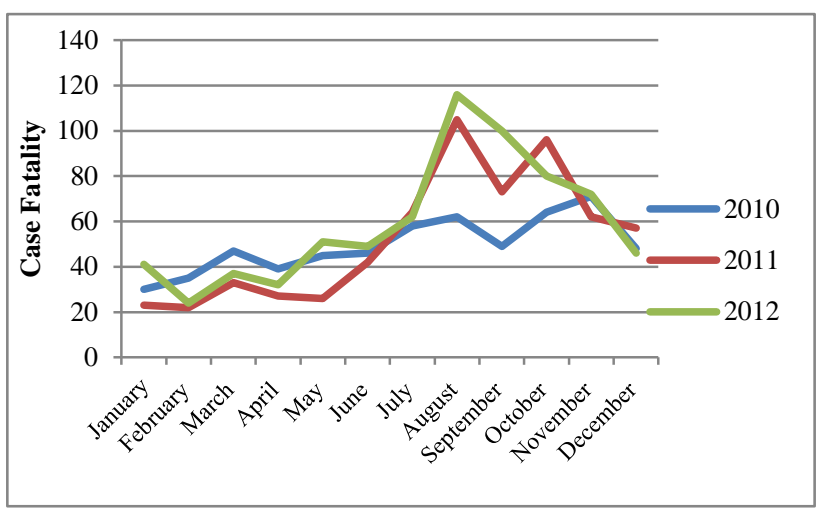

Figure 1:Month-wise fatalities due to malaria $(\mathbf{n}=1934)$.

\section{DISCUSSION}

The analysis of cases admitted to SCBMCH over the three study years 2010-2012, shows an increasing trend. This is in keeping with the increasing population and availability of improved road communication and transport facilities. P. Muentener et al showed that total incidence of malaria infections in Europe increased from 6840 in 1985 to 7244 in 1995 with a peak of 8438 in 1989 which relate to our study. ${ }^{5}$ In a study by Serign
Ceesay et al at a tertiary care hospital at Gambia found that a substantial decrease in the yearly number of admissions and deaths attributed to malaria. ${ }^{6}$ Compared with $2003,74 \%$ reduction in the proportion of malaria cases admitted in 2007 at that hospital. At Mehsana district of north Gujrat B. Prajapati et al found that there is gradual decrease in malaria cases from 1999 to $2004 .^{7}$ Both these finding are contradict to findings of this study.

In contrast to absolute number of deaths the case fatality ratio shows a steady decline in clinical malaria. The case fatality ratio of clinical malaria was $0.31,0.24$ and 0.21 for 2010, 2011 and 2012 respectively. The cumulative case fatality ratio was 0.24 . The numbers of fatalities have registered an increasing trend over the three years. This correlates with the increased numbers of patients admitted to this institution. P. Muentener et al found that for the period 1977-86 the average malaria CFR for Europe as a whole was $1.1 \%$. Germany had a high CFR around 3.66. ${ }^{5}$ The overall case fatality of $0.6 \%$ among all malaria cases in Alipurduar, west Bengal was found in a study by Sarkar et al is higher than in our study. ${ }^{8}$

The proportional mortality rate shows a steady decline over the years in malaria cases. Proportional mortality rate due to malaria was $8.97 \%$ for three years. It was $9.28 \%$ for the year $2010,8.90 \%$ for the year 2011 and $8.79 \%$ for the year 2012 . The proportional mortality rate shows a steady decline over the years in malaria cases. $\mathrm{O}$. O. Ayoola et al at University College Hospital in Ibadan showed that malaria contribute to $6.2 \%$ (73 of 1185 deaths) of the total deaths in that hospital. ${ }^{9}$ At Papua, Indonesia Emilian Tjitra et al found that total of 242 in patients with malaria died, accounting for $15 \%$ $(242 / 1,608)$ of all cause inpatient mortality over the same period. $^{10}$

The analysis of the data of the seasonal (monthly) distribution of fatalities shows that the peak of the case load is from the month of June onwards and the upward swing of the case load continues up to October and then tapers down with a small secondary peak in late November and December. This period of peak case load coincides well with the transmission dynamics of the malaria parasite observed in the community and thus attests the dominant seasonal activity of the malaria in the community even though the base transmission of the parasite is perennial as observed from the malaria cases coming to this institution round the year. B. Prajapati et al at Mehsana district of north Gujarat found that the maximum number of cases was reported in month of august and September which conclude that malaria is a seasonal disease. ${ }^{7}$ At a tertiary referral centre in south Canara of Karnataka Madhu Muddaih et al showed that no of admissions due to malaria increased from June onwards coinciding the monsoon season. N. Pemola Devi et al at Dehradun, Uttaranchal showed that with regard to monthly variations in the incidence of malaria cases the peak seasons were monsoon and post monsoon i.e. June to september. ${ }^{11,12}$ Although incidence occurred 
between may to November but during the winter months (December to February) it was almost negligible. So, seasonal variation in incidence of malaria is nearly similar in all studies.

In this study we found that fatality in males outnumbered females while being treated for clinical malaria in this institution for consecutive three years (2010, 2011 and 2012). The preponderance of males noteworthy since the ratio of fatality between the sexes (male: female) is 3:2 in three years. It may be due to gender issues related to health-seeking behaviours prevalent in the society. Also it may be due to exposure of their body to mosquito bite as they have habit of to cover body not properly. N. G. Das et al at Sonitpur district of Assam found that overall malaria prevalence was higher among the males than (SPR 43.2\%) than in females (SPR 34.5\%). ${ }^{13}$ Madhu Muddaih et al found that males $(81 \%)$ were most affected compared to women (19\%) which is similar to our study. ${ }^{35}$ At central coast of India Dhangadamajhi G. et al showed that no of malaria infection by gender did not show any significant difference indicating no deviation from random distribution pattern of the malaria parasites. $^{14}$

\section{CONCLUSION}

Trends of malarial deaths show that malaria continues to be one of the largest contributors of institutional mortality. In absolute numbers the trend of cases shows an increase in fatal cases over the study year's i.e 20102012. A proper system of record keeping is necessary especially at a tertiary level health institute. Strengthening of the MRD department can go a long way not only in understanding the trend of malaria but also a host of other health problems affecting the population of the state

Funding: No funding sources Conflict of interest: None declared

Ethical approval: The study was approved by the Institutional Ethics Committee

\section{REFERENCES}

1. Park K. Park's text book of preventive and social medicine. $22^{\text {nd }}$ ed. Bhanot Publications, Jabalpur India. 2013.

2. National Vector Borne Disease Control Programme. Treatment of Malaria. NVBDCP. 2013;2(2).
3. Program implementation plan 2009-10. NRHM Odisha. Available at http:/www.mohfw.nic.in/NRHM/PIP_09_10/Odisha /NVBDCP_Text.pdf.

4. WHO. World Health Statistics, 2012.

5. Muentener P, Schlagenhauf P, Steffen R. Imported malaria 1985-1995: trends and perspectives. Bulletin of the World Health Organization. 1999;77(7).

6. Cessay SJ, Erskine J. Changes in malaria indices between 1999 and 2007 in the gambia: a retrospective analysis. The lancet. 2008;372.

7. Prajapati B, Patel A, Patel M. Study of hospital based malaria cases in mehsana district of north gujrat. Internet Scientific Publication. 2006;5:1.

8. Sarkar J, Shah NK, Murhekar MV. Incidence, management, and reporting of severe and fatal Plasmodium falciparum malaria in secondary and tertiary health facilities of Alipurduar, India .2009. J Vector Borne Dis. 2012;49:157-63.

9. Ayoola OO, Orimadegun AE, Akinsola AK, Osinsui K. A five-year review of childhood mortality at the University College Hospital, Ibadan. West Afr J Med. 2005;24:2.

10. Tjitra E, Anstey NM, Sugiarto P, Warikar N, Kenangalem E. Multidrug resistant plasmodium vivax associated with severe and fatal malaria: a prospective study in papua, Indonesia. PloS Med. 2008;5(6):e128.

11. Muddaiah M, Prakash PS. A study of clinical profile of malaria in a tertiary referral centre in South Canara. J Vect Borne Dis. 2006;43:29-33.

12. Devi PN, Jauhari RK. Climatic variables and malaria incidence in Dehradun, Uttaranchal, India. J Vect Borne Dis. 2006;43:21-8.

13. Das NG, Talukdar PK, Khalita J, Baruah I, Sribastava I. Malaria situation in forest fringed villages of sonitpur district, Assam, India. bordering Arunachal Pradesh during an outbreak. J Vect Borne Dis. 2007;44:213-8.

14. Dhangadamajhi G, Kar SK, Ranjit MR. High prevalence and gender bias in distribution of Plasmodium malariae infection in central east-coast India. Tropical Biomedicine. 2009;26(3):326-33.

Cite this article as: Kamble NH, Dash MK, Satapathy DM. Trend of malarial deaths admitted in medicine wards of a tertiary care centre at Cuttack, Odisha, India. Int J Community Med Public Health 2016;3: 1409-12. 